\title{
Prevention of acute knee injuries in adolescent female football players: cluster randomised controlled trial
}

\author{
@ $(0 \Theta$ OPEN ACCESS
}

\author{
Markus Waldén senior researcher ${ }^{12}$, Isam Atroshi associate professor ${ }^{23}$, Henrik Magnusson \\ statistician $^{4}$, Philippe Wagner statistician ${ }^{5}$, Martin Hägglund senior researcher ${ }^{4}$
}

'Division of Community Medicine, Department of Medical and Health Sciences, Linköping University, 58183 Linköping, Sweden; ${ }^{2}$ Department of Orthopaedics, Hässleholm-Kristianstad-Ystad Hospitals, 28125 Hässleholm, Sweden; ${ }^{3}$ Department of Clinical Sciences, Lund University, 22184 Lund, Sweden; ${ }^{4}$ Division of Physiotherapy, Department of Medical and Health Sciences, Linköping University; ${ }^{5}$ National Competence Centre for Musculoskeletal Disorders, Lund University

\begin{abstract}
Objective To evaluate the effectiveness of neuromuscular training in reducing the rate of acute knee injury in adolescent female football players.

Design Stratified cluster randomised controlled trial with clubs as the unit of randomisation
\end{abstract}

Setting 230 Swedish football clubs (121 in the intervention group, 109 in the control group) were followed for one season (2009, seven months).

Participants 4564 players aged 12-17 years (2479 in the intervention group, 2085 in the control group) completed the study.

Intervention 15 minute neuromuscular warm-up programme (targeting core stability, balance, and proper knee alignment) to be carried out twice a week throughout the season.

Main outcome measures The primary outcome was rate of anterior cruciate ligament injury; secondary outcomes were rates of severe knee injury ( $>4$ weeks' absence) and any acute knee injury.

Results Seven players $(0.28 \%)$ in the intervention group, and $14(0.67 \%)$ in the control group had an anterior cruciate ligament injury. By Cox regression analysis according to intention to treat, a $64 \%$ reduction in the rate of anterior cruciate ligament injury was seen in the intervention group (rate ratio $0.36,95 \%$ confidence interval 0.15 to 0.85 ). The absolute rate difference was -0.07 (95\% confidence interval -0.13 to 0.001 ) per 1000 playing hours in favour of the intervention group. No significant rate reductions were seen for secondary outcomes.

Conclusions A neuromuscular warm-up programme significantly reduced the rate of anterior cruciate ligament injury in adolescent female football players. However, the absolute rate difference did not reach statistical significance, possibly owing to the small number of events.

Trial registration Clinical trials NCT00894595.

\section{Introduction}

Football (soccer) is the most popular sport worldwide with around 265 million players, and the number of female players is growing rapidly. ${ }^{1}$ For example, more than three million young people play football in the United States alone, and almost half of them are female ${ }^{2}$; and in 2006 around 83000 female football players from the age of 12 years were registered in Sweden (population around 9 million). ${ }^{3}$ Unfortunately, knee injuries are common, and severe injuries such as anterior cruciate ligament injury constitute a serious problem in terms of long absence from or termination of football and early osteoarthritis. ${ }^{4-8}$

In football, the rate of anterior cruciate ligament injury is more than twofold higher in female players than in male players, ${ }^{9} 10$ and adolescent girls are especially at risk. ${ }^{10}{ }^{11}$ Several parallel group controlled studies, most targeting adolescents, have evaluated injury prevention strategies in female football players. ${ }^{12-21}$ Only two non-randomised studies in adolescent footballers showed significant reduction of acute knee injuries or non-contact anterior cruciate ligament injuries with neuromuscular warm-up programmes. ${ }^{16}{ }^{17}$ However, most studies were not designed specifically to evaluate preventive effects on knee or anterior cruciate ligament injury as the primary outcome, and high quality randomised controlled trials targeting prevention of acute knee injuries or anterior cruciate ligament injuries are lacking. ${ }^{22}$

The main objective of our stratified cluster randomised controlled trial was to evaluate the effectiveness of a neuromuscular warm-up programme in reducing the rate of acute knee injury, particularly anterior cruciate ligament injury, in adolescent female football players. Our hypothesis was that the rates of anterior cruciate ligament injury and acute knee injury would be significantly reduced in the intervention group compared with the control group. 


\section{Methods}

\section{Study design and participants}

The study was a two armed, parallel group, cluster randomised controlled trial. In accordance with most previous studies, ${ }^{12} 1315-21$ we chose a cluster design as the intervention was implemented in a team setting and to minimise contamination between the intervention and control groups. The study protocol has been published, ${ }^{22}$ and the data collection procedures and definitions used follow international guidelines for surveillance of football injuries. ${ }^{23} 24$

We recruited clubs from the female under 14 to under 18 series (age 12-17 years) in eight regional districts of the Swedish Football Association (Blekinge, Bohuslän, Skåne, Småland, Södermanland, Västmanland, Örebro, and Östergötland), all located in the middle and southern parts of Sweden for logistical reasons. After obtaining enrolment registries for the 2009 campaign, two authors (MW and $\mathrm{MH}$ ) contacted eligible coaches between December 2008 and February 2009. We excluded clubs that did not respond to the invitation or declined participation, those that had fewer than two training sessions a week, and those already using an injury prevention programme.

We randomised all clubs that agreed to participate into an intervention or control group. We used a computer generated list of random numbers to randomise clubs stratified by district, whereby all teams from the same club were assigned to the same group. We chose stratification by district to account for variations in league systems (for example, by competitive or age level) between districts. One author (IA) who was blinded to the identity of the clubs did the randomisation. The randomisation procedure aimed to achieve a balanced number of clubs in the intervention and control groups, considering that the clubs had different number of teams. Randomisation was revealed after recruitment of the final club to ensure concealment of allocation.

\section{Intervention}

Our intervention was a neuromuscular warm-up programme (Knäkontroll, SISU Idrottsböcker, Sweden, 2005) containing exercises focusing on knee control and core stability similar to other programmes in, for example, team handball at that time. ${ }^{25}$ The six exercises were a one legged knee squat, a pelvic lift, a two legged knee squat, the bench, the lunge, and jump/landing technique. ${ }^{22}$ Each exercise is subdivided into four steps of progressive difficulty and a pair exercise (table $1 \Downarrow$ ). The exercises were preceded by 5 minutes of low intensity running and took about 15 minutes to complete after familiarisation. The intervention clubs were instructed to do the exercises during the warm-up at two training sessions a week throughout the whole season. All players started on the first level of difficulty and proceeded to the next level when exercises were performed with good control as assessed by the coach.

\section{Study procedures and outcomes}

We recruited 68 physiotherapists (study therapists) and eight physicians (study physicians) to serve as medical support to the clubs. The study therapists assisted coaches with data collection and recorded injuries in the two groups. The study physicians assisted the study therapists in diagnosing injuries. Two authors (MW and MH) held instructional regional meetings for coaches in both groups in each district, briefing them about the study procedures. Thereafter, a study therapist gave practical instructions about the exercises to one coach and a player from each team in the intervention clubs. Each coach also received a CD-ROM and a leaflet describing the programme. Coaches who could not attend the meetings were given the same verbal and written information by their study therapist before the start of the trial, and coaches in the intervention group also received the practical exercise instructions. During the practical demonstration of the exercises, study therapists instructed the coaches carefully on how to clear players to progress to the next level of difficulty - that is, when all repetitions were performed with good neuromuscular control, mainly focusing on core stability and proper knee alignment. Control group coaches were instructed to train and play as usual throughout the 2009 season without any changes.

We collected data during the competitive season (1 April to 31 October 2009). Injury surveillance included a baseline questionnaire, players' attendance, and injury registration. The baseline questionnaire included name, social security number, anthropometrics, menarche, previous acute knee injuries, current knee complaints, and family history of anterior cruciate ligament injury. The coach registered individual playing time (registered as minutes of actual participation for each player) and absences (due to acute knee injury or other reasons) for each training session and match during the season on a computer based player's attendance form and emailed the data monthly to the study therapist and authors (MW and $\mathrm{MH}$ ). If a player had additional playing time with a district or national team or another team within the club, this was also registered on the attendance form. Participation in other sports or leisure time activities was not recorded. The coach reported acute knee injuries to the study therapist, who evaluated the injury in person and documented it on an injury report form. A recordable acute knee injury was one that occurred during football training or match play, had a sudden onset, and led to a player being unable to participate fully in future training or match play (excluding contusions). ${ }^{22}$ A severe injury was one that caused absence of more than four weeks. We regarded injuries as non-contact if they occurred without contact with another player or object (excluding the playing surface). ${ }^{22}$ We defined an anterior cruciate ligament injury as a first or recurrent partial or total rupture of the ligament either in isolation or associated with concomitant injuries to the knee joint. ${ }^{5}$ If an anterior cruciate ligament injury was suspected or the diagnosis was unclear from the study therapist's examination, the player was referred to a study physician for further evaluation. Players with possible anterior cruciate ligament injury were offered examination with magnetic resonance imaging. Use of magnetic resonance imaging was not mandatory to confirm other knee injuries if anterior cruciate ligament injury could be ruled out clinically. If any information was missing or was unclear, we contacted the coach or player for further clarification.

The coaches, players, and study therapists were not blinded to group allocation, but the study physicians who assessed the primary outcome were. Two authors (PW and IA) who were not involved in the intervention or data collection did the intention to treat analysis with group identity concealed.

\section{Compliance}

The coaches in the intervention group documented the execution of the warm-up programme on the players' attendance forms for each training session. Study therapists made two unannounced visits to each intervention team to monitor compliance and execution of the programme. We instructed the therapists to observe the beginning of the training session out of sight of the on-field coach. After having observed the execution of the warm-up programme, the therapists corrected 
any training errors. Except for these two unannounced visits, no other supervision of coaches was carried out.

\section{Statistical methods}

The primary outcome was the rate of anterior cruciate ligament injury; secondary outcomes were the rates of severe knee injury and any acute knee injury. ${ }^{22}$ We did the pre-trial sample size calculation without accounting for clustering and based it on an annual/seasonal incidence of anterior cruciate ligament injury of $1.15 \%$ in female adolescent football players. ${ }^{22}$ With a power of $80 \%$ and an estimated reduction of anterior cruciate ligament injury by $50 \%$ in the intervention group, we aimed to recruit 8118 players (4059 in each group).

The unadjusted intention to treat analysis used Cox regression with robust standard error estimation to estimate the rate ratio between groups and corresponding $95 \%$ confidence interval, in accordance with Lin and Wei. ${ }^{26} \mathrm{We}$ used the robust standard error estimate to account for the correlation of outcomes within each club. We used Wald's test to calculate P values. We used the same method to do subgroup efficacy analyses for compliant players (defined as having carried out at least one intervention session a week on average), adjusting for the pre-specified covariates age, menarche, previous acute knee injury, match frequency, and match play with other teams. As a sensitivity analysis, we also analysed the primary outcome by using a shared frailty Cox regression model with club as the frailty effect. We checked for possible deviation from the proportional hazards assumption of the Cox regression model by using the non-proportionality test on the basis of the Schoenfeldt residuals. We calculated the absolute rate reduction with $95 \%$ confidence interval for the primary outcome as a crude estimate of the rate difference by using the Mantel-Haenszel method according to Greenland and Rothman. ${ }^{27}$ This corresponds to a standardised rate difference with weights that depend on the number of player hours in the intervention and control groups of each stratum. In contrast to the Cox regression, this method makes the simplifying assumption that the rate is constant over time in each group. We calculated the number needed to treat for the primary outcome as the inverted absolute rate reduction. We estimated the intra-cluster correlation coefficient for the primary outcome by using generalised estimating equations assuming an exchangeable correlation structure, Poisson distribution, and a log link function. We stratified all analyses by district because of the stratification of the randomisation procedure. We did no interim analyses. We used mean (standard deviation) to make between group comparisons for anthropometric data and exposures. We calculated time to medical attention as median (interquartile range). All tests were two sided with a significance level of $<0.05$. We used Stata version 11.0 for analyses.

\section{Results \\ Study population}

The target population consisted of 414 eligible clubs that we approached for recruitment; 309 clubs (range 1-5 teams in each club) accepted and were randomised into intervention and control groups (figure $\Downarrow$ ). Shortly after randomisation, 18 (6\%) clubs were dissolved before entering league play owing to a shortage of players. Excluding these clubs, the dropout frequency was $21 \%$ (intervention $16 \%$ (23/144 clubs), control $26 \%$ (38/147 clubs)). We obtained consent for 4564 players, and 65 players declined participation. The players in the two groups who completed the study were similar in terms of baseline characteristics (table $2 \Downarrow$ ).

\section{Acute knee injuries}

During 278298 football hours (intervention 149214 hours, control 129084 hours), 96 knee injuries (intervention 49, control 47) in 92 players (intervention 48, control 44) were recorded. Twenty-one anterior cruciate ligament injuries occurred in 21 $(0.46 \%)$ players, of whom $7(0.28 \%)$ were in the intervention group and $14(0.67 \%)$ were in the control group (table $3 \Downarrow$ ). Fifty-seven severe knee injuries (22 collateral ligament or capsular sprains, 21 anterior cruciate ligament injuries, 7 patella dislocations or subluxations, 6 meniscus or chondral lesions, and 1 tibia plateau fracture) occurred in 57 players (intervention 26 , control 31). No injury occurred during the execution of the warm-up programme.

The medical support supplied to the clubs evaluated 86 (90\%) of the 96 injuries. Eight injuries were treated at a local emergency department without notification of the study therapist at occurrence of the injury. Two injured players did not seek medical attention at the time of injury, and the diagnoses were based on study therapists' examinations and players' interviews after return to play. The median elapsed time from injury to examination by the study's medical support was 4 (interquartile range 2-8) days; for anterior cruciate ligament injuries it was 3 (2-6) days. Magnetic resonance imaging or arthroscopy was done for 20 of the 21 anterior cruciate ligament injuries and for 36 of the 57 severe injuries.

\section{Effectiveness of neuromuscular warm-up programme}

The unadjusted Cox regression according to intention to treat showed a statistically significant $64 \%$ reduction in the rate of anterior cruciate ligament injury in the intervention group compared with the control group (rate ratio $0.36,95 \%$ confidence interval 0.15 to $0.85, \mathrm{P}=0.02$ ) (table $4 \Downarrow$ ). The sensitivity analysis, using a shared frailty Cox regression model, yielded almost identical results (rate ratio $0.36,0.14$ to 0.91 , $\mathrm{P}=0.03$ ). We detected no statistically significant deviation from the proportionality assumption for the Cox regression model $(\mathrm{P}=0.232)$. The estimated intra-cluster correlation coefficient for the primary outcome was negative $(-0.0026)$ and hence given the value 0 . The absolute rate difference for the primary outcome was -0.07 (95\% confidence interval -0.13 to 0.001 ) per 1000 playing hours in favour of the intervention group, and the corresponding number needed to treat was 14 .

We found no significant rate reductions for secondary outcomes (table $4 \Downarrow$ ). The adjusted subgroup analyses of compliant players (1303 players in 112 intervention group clubs, 1967 players in 106 control group clubs) showed a statistically significant $83 \%$ rate reduction in anterior cruciate ligament injury (rate ratio $0.17,0.05$ to $0.57, \mathrm{P}=0.004$ ), as well as significant reductions for secondary outcomes in the intervention group compared with the control group (severe knee injury rate ratio $0.18,0.07$ to $0.45, \mathrm{P}<0.001$; any acute knee injury rate ratio $0.53,0.30$ to $0.94, \mathrm{P}=0.03$ ). Finally, exploratory analyses of non-contact anterior cruciate ligament injuries showed a reduction in rates favouring the intervention group. The reduction was statistically significant only for the adjusted subgroup analysis of compliers (intention to treat analysis rate ratio $0.40,0.13$ to $1.18, \mathrm{P}=0.10$; adjusted subgroup analysis rate ratio $0.26,0.07$ to 0.99 , $\mathrm{P}=0.049$ ).

\section{Discussion}

The principal finding in this cluster randomised controlled trial was that a 15 minute neuromuscular warm-up programme reduced the overall rate of anterior cruciate ligament injury in 
adolescent female football players by $64 \%$. Additionally, we saw a preventive effect for severe knee injury and any acute knee injury in players who completed the programme at least once a week (compliers).

\section{Prevention of knee injury}

Of the previous controlled studies that evaluated neuromuscular training programmes in adolescent female football players, ${ }^{12}{ }^{14-20}$ only two non-randomised studies have shown preventive effects - one on hospital treated acute knee injuries and the other on non-contact anterior cruciate ligament injuries. ${ }^{16}{ }^{17}$ However, most previous studies were too small to show preventive effects on knee injuries, and this, together with poor compliance by players, might have been an important reason why they failed to show an effect. We found a reduction in the overall rate of anterior cruciate ligament injury by almost two thirds according to a stratified Cox regression model, and the result was replicated in a sensitivity analysis. The number needed to treat was 14 , meaning that for every 14 players who receive the warm-up programme one less anterior cruciate ligament injury would occur per 1000 playing hours. However, as the absolute rate difference according to the Mantel-Haenszel method did not reach statistical significance, the number needed to treat should be interpreted with caution. ${ }^{28}$ We believe that the main reason for the discrepancy between the statistically significant rate ratio from the Cox regression model and the non-significant absolute rate difference according to the Mantel-Haenszel method is that this last method, besides the constant rate assumption, can exhibit lower statistical precision. ${ }^{27} \mathrm{We}$ chose the Mantel-Haenszel method in spite of this drawback, as it is recommended to avoid possible bias when the number of events is low. ${ }^{27}$

In accordance with previously evaluated neuromuscular programmes, the exercises evaluated in this study targeted leg and core muscles, balance, landing technique, and proper knee alignment. The rationale for including such exercises in prevention programmes for anterior cruciate ligament injury is that lateral trunk displacement and excessive dynamic knee valgus have been found to be risk factors for this type of injury. ${ }^{29}{ }^{30}$ Because most anterior cruciate ligament injuries in football players are believed to result from non-contact injury mechanisms, ${ }^{5}$ neuromuscular preventive programmes have primarily targeted non-contact injuries. However, having proper neuromuscular control might also help to protect the knee from injury after a gentle push to the trunk or a fair shoulder to shoulder tackle. We therefore chose to include all anterior cruciate ligament injuries regardless of mechanism of injury as the primary outcome in our trial. In an exploratory analysis of non-contact anterior cruciate ligament injury, we found no significant effect $(\mathrm{P}=0.10)$ even though the point estimate (rate ratio 0.40 ) suggests a reduction of the same magnitude as for the primary outcome. Interestingly, five of the anterior cruciate ligament injuries occurred during football training, all of which were non-contact in nature and occurred in the control group. This suggests that non-contact anterior cruciate ligament injuries during training may be preventable with the neuromuscular training programme. The finding is consistent with a previous study on female collegiate football players, in which the preventive effect was seen only for training related anterior cruciate ligament injuries. ${ }^{13}$

\section{Strengths and limitations of study}

To our knowledge, this study is the largest randomised controlled trial of injury prevention in sports to date, involving more than 4500 players. Some important strengths of the trial include cluster randomisation of clubs to avoid contamination between the intervention and control groups, individual playing time registration with no missing data for analysed clubs, careful monitoring of compliance, blinded analysts, and no involvement of the authors in the development of the programme. Additionally, the medical support supplied through the study enabled quick and qualified examination of injuries by experienced sports medicine practitioners, and the study physicians who verified the primary outcome were blinded to group allocation.

This trial also has some limitations. Firstly, the estimation of the sample size was not based on a conventional calculation for cluster randomised controlled trials, as valid data for rates of anterior cruciate ligament injury based on playing time, and corresponding intra-cluster correlation coefficients, in adolescent female football players were lacking in the literature. ${ }^{22}$

Consequently, estimating the intra-cluster correlation coefficient and the inflation factor a priori was difficult. Secondly, we did not recruit the estimated sample according to our sample size calculation, as the number of clubs that were excluded before randomisation (105 clubs), that were dissolved shortly after randomisation owing to shortage of players (18 clubs), or that dropped out during the season (61 clubs) was higher than expected. A lower than expected seasonal incidence of anterior cruciate ligament injury $(0.67 \% v 1.15 \%$ according to pre-trial sample size calculation) also contributed to a limited number of anterior cruciate ligament injuries being recorded. However, we believe that the number of players included achieved the purpose of the study, even though we acknowledge that a larger sample would have added further strength to our study.

Thirdly, a possibility of selection bias exists because clubs that initially chose to participate (and intervention clubs that continued through the whole study period) may have been more motivated to follow the neuromuscular training regime than clubs that did not respond to the invitation, declined participation, or dropped out during the study. Although providing a reason for leaving the study was not necessary (according to research ethics), a plausible factor contributing to the high dropout frequency might be unwillingness to complete the individual playing time registration, as this puts substantial strain on the recorders. In line with findings in other recent trials on adolescent football players, ${ }^{12}{ }^{19} 20$ the dropout frequency was higher in the control group, possibly indicating disappointment with group allocation. Fourthly, we have no data on the number of players in the non-participating clubs, as reliable statistics on the number of eligible players in each district in the target age groups were lacking. However, on the basis of the average squad size of the participating clubs, we estimate that approximately 6500 players were randomised in the trial.

Fifthly, the study therapists had several assignments, including monitoring compliance and evaluating knee injuries, and they were thus not blinded to group allocation. However, recruitment of additional physiotherapists specifically to examine the knee injuries was not possible. Sixthly, we set the cut-off threshold for players' compliance at performance of at least one intervention session a week. This is arguably rather low, but it was based on the fact that most clubs had two weekly training sessions; and a recent Norwegian trial on adolescent female football players reported average attendance of around $60 \%$, and the average player's compliance in the intervention group in that study was 0.8 sessions a week. ${ }^{19}$ All compliance data were reported by coaches on the players' attendance forms, but we were unable to validate the coaches' reports except for the two unannounced visits by the study therapists. Furthermore, 
the progression of the exercises was done under the supervision of the coach without any guidance by the study therapists during the season, and the extent to which the intervention clubs used the programme with fidelity and progressed through the programme as intended is uncertain. We chose this approach to resemble a real world situation, where no such external professional resources would be available to youth football clubs.

Finally, we had no control over whether any of the control group clubs performed exercises similar to our intervention programme during the study period, despite coaches having stated at study inclusion that they did not do any such exercises and the fact that they were instructed to carry out their usual training as normal during the season without any changes. However, any possible bias introduced by such contamination of the control group would lead to underestimation of the preventive effect found in our study.

\section{Implications and applicability}

The number of female football players, a high risk group from a knee injury perspective, is growing rapidly worldwide. Successful preventive measures in football could thus have a substantial effect on the injury burden and also dramatically diminish the costs associated with treatment. The direct costs of surgery and hospital care for anterior cruciate ligament reconstructions are high, ${ }^{31}{ }^{32}$ and additional costs are associated with non-surgical treatment, postoperative rehabilitation, and disability claims. Consequently, if almost two thirds of the anterior cruciate ligament injuries in adolescent female football players were avoided, this would substantially reduce the need for surgery and rehabilitation with large health economic benefits. Future efforts should include cost-benefit analyses of neuromuscular training programmes, as well as implementation research identifying motivators and barriers (among coaches and players) to adoption of such training programmes.

Whether our results can be generalised to other age groups, male football players, or other team sports is uncertain. However, similar neuromuscular programmes have shown preventive effects in other cluster randomised controlled trials for training related anterior cruciate ligament injuries in female collegiate football players, ${ }^{13}$ as well as on lower extremity injury in adolescent female football players, ${ }^{19}$ team handball players (mainly female), ${ }^{25}$ and adult female floorball players. ${ }^{33}$ Therefore, assuming that the programme might be also effective in other football populations as well as in other sports is reasonable.

We thank the study assistants from the Swedish Football Association (Per Renström, professor, Annica Näsmark, physiotherapist, and Anneli Gustafsson, football coach) for their general help with the study, and Jonas Ranstam, senior bio-statistician, for statistical advice. We also thank the coaches and all players who participated in the study, as well as the study therapists and study physicians.

Contributors: MW, IA, and MH were responsible for the conception and design of the study. MW and $\mathrm{MH}$ coordinated the study and managed all aspects, including data collection. HM provided technical support and was responsible for database management. PW did the analyses, which were planned and checked with the other authors. MW, IA, and $\mathrm{MH}$ wrote the first draft of the manuscript. All authors had full access to all data and contributed to interpretation of the findings and critical revision of the manuscript. $\mathrm{MW}$ and $\mathrm{MH}$ are the guarantors.

Funding: The study was financially supported by the Swedish Football Association and the Folksam Insurance Company. This research also received grants from the Swedish National Centre for Research in Sports and from the Hässleholm Hospital. None of the sponsors had any role in the design or conduct of the study; the collection, analysis, and interpretation of the data; or the preparation, approval, and submission of the manuscript. No author or related institution has received any financial benefit from research in this study.

Competing interests: All authors have completed the Unified Competing Interest form at www.icmje.org/coi_disclosure.pdf (available on request from the corresponding author) and declare: $\mathrm{MW}, \mathrm{HM}$, and $\mathrm{MH}$ had financial support from the Swedish Football Association and the Folksam Insurance Company; MW and MH received research grants from the Swedish National Centre for Research in Sports and IA received a grant from the Hässleholm Hospital for the submitted work; MW and MH have been paid by the Swedish Football Association for constituting the medical staff of the Swedish male under 19 national team; no other relationships or activities that could appear to have influenced the submitted work.

Ethical approval: The study was approved by the regional ethical review board in Linköping (M197-08). Players and parents or guardians gave individual written informed consent.

Data sharing: No additional data available.

1 Fédération Internationale de Football Association. FIFA Big Count 2006: 270 million people active in football. 2007. www.fifa.com/aboutfifa/organisation/media/news/ newsid=529882/index.html.

2 United States Youth Soccer Association. Largest youth sports organization celebrates 35th anniversary. 2009. www.usyouthsoccer.org/aboutus/History.asp.

3 Swedish Football Association. Rekordmånga fotbollsspelare i Sverige [Record number of football players in Sweden]. 2006. http://svenskfotboll.se/arkiv/tidigare/2006/11/ rekordmanga-fotbollsspelare-i-sverige/.

4 Söderman K, Pietilä T, Alfredson H, Werner S. Anterior cruciate ligament injuries in young females playing soccer at senior levels. Scand J Med Sci Sports 2002;12:65-8.

5 Waldén M, Hägglund M, Magnusson H, Ekstrand J. Anterior cruciate ligament injury in elite football: a prospective three-cohort study. Knee Surg Sports Traumatol Arthrosc 2011;19:11-9.

6 Lohmander LS, Östenberg A, Englund M, Roos H. High prevalence of knee osteoarthritis, pain, and functional limitations in female soccer players twelve years after anterior cruciate ligament injury. Arthritis Rheum 2004;50:3145-52.

7 Von Porat A, Roos EM, Roos H. High prevalence of osteoarthritis 14 years after an anterior cruciate ligament tear in male soccer players: a study of radiographic and patient relevant outcomes. Ann Rheum Dis 2004;63:269-73.

8 Øiestad BE, Engebretsen L, Storheim K, Risberg MA. Knee osteoarthritis after anterior cruciate ligament injury: a systematic review. Am J Sports Med 2009;37:1434-43.

9 Prodromos CC, Han Y, Rogowski J, Joyce B, Shi K. A meta-analysis of the incidence of anterior cruciate ligament tears as a function of gender, sport, and a knee injury-reduction regimen. Arthroscopy 2007;23:1320-5.

10 Waldén $\mathrm{M}$, Hägglund $\mathrm{M}$, Werner J, Ekstrand J. The epidemiology of anterior cruciate ligament injury in football (soccer): a review of the literature from a gender-related perspective. Knee Surg Sports Traumatol Arthrosc 2011;19:3-10.

11 Shea KG, Pfeiffer R, Wang JH, Curtin M, Apel PJ. Anterior cruciate ligament injury in pediatric and adolescent soccer players: an analysis of insurance data. $J$ Pediatr Orthop 2004;24:623-8.

12 Emery CA, Meeuwisse WH. The effectiveness of a neuromuscular prevention strategy to reduce injuries in youth soccer: a cluster-randomised controlled trial. Br J Sports Med 2010;44:555-62.

13 Gilchrist J, Mandelbaum BR, Melancon H, Ryan GW, Silvers HJ, Griffin LY, et al. A randomized controlled trial to prevent noncontact anterior cruciate ligament injury in female collegiate soccer players. Am J Sports Med 2008;36:1476-83.

14 Heidt RS Jr, Sweeterman LM, Carlonas RL, Traub JA, Tekulve FX. Avoidance of soccer injuries with preseason conditioning. Am J Sports Med 2000;28:659-62.

15 Hewett TE, Lindenfeld TN, Riccobene JV, Noyes FR. The effect of neuromuscular training on the incidence of knee injury in female athletes. Am J Sports Med 1999;27:699-706.

16 Kiani A, Hellquist E, Ahlqvist K, Gedeborg R, Michaëlsson K. Prevention of soccer-related knee injuries in teenaged girls. Arch Intern Med 2010;170:43-9.

17 Mandelbaum BR, Silvers HJ, Watanabe DS, Knarr JF, Thomas SD, Griffin LY, et al. Effectiveness of a neuromuscular and proprioceptive training program in preventing Effectiveness of a neuromuscular and proprioceptive training program in preventing
anterior cruciate ligament injuries in female athletes. Am J Sports Med 2005;33:1003-10.

18 Pfeiffer RP, Shea KG, Roberts D, Grandstrand S, Bond L. Lack of effect of a knee ligament injury prevention program on the incidence of noncontact anterior cruciate ligament injury. J Bone Joint Surg Am 2006;88:1769-74.

19 Soligard T, Myklebust G, Steffen K, Holme I, Silvers H, Bizzini M, et al. A comprehensive warm-up programme to prevent injuries in young female footballers: cluster randomised controlled trial. BMJ 2008;337:a2469.

20 Steffen K, Myklebust G, Olsen OE, Holme I, Bahr R. Preventing injuries in female youth football—a cluster-randomised controlled trial. Scand J Med Sci Sports 2008;18:605-14.

21 Söderman K, Werner S, Pietelä T, Engström B, Alfredson H. Balance board training: prevention of traumatic injuries of the lower extremities in female soccer players? A prospective randomized intervention study. Knee Surg Sports Traumatol Arthrosc 2000;8:356-63.

22 Hägglund $M$, Waldén $M$, Atroshi I. Preventing knee injuries in adolescent female football players-design of a cluster randomized controlled trial [NCT00894595]. BMC Musculoskeletal Disorders 2009;10:75.

23 Fuller CW, Ekstrand J, Junge A, Andersen TE, Bahr R, Dvorak J, et al. Consensus statement on injury definitions and data collection procedures in studies of football (soccer) injuries. Br J Sports Med 2006;40:193-201. 


\section{What is already known on this topic}

Knee injuries are common in football regardless of the playing level, and adolescent female players are more susceptible to anterior cruciate ligament injury than their male counterparts

Several parallel group controlled studies have evaluated different injury prevention strategies in adolescent female football players However, few studies have shown statistically significant reductions of knee injury or anterior cruciate ligament injury with neuromuscular training

\section{What this study adds}

A 15 minute neuromuscular warm-up programme reduced the overall rate of anterior cruciate ligament injury by $64 \%$ in adolescent female football players

Players who carried out the programme at least once a week (compliers) additionally had lower rates of severe knee injury ( $>4$ weeks' absence) and any acute knee injury

Neuromuscular training should be part of the warm-up programme for young female football players

24 Hägglund M, Waldén M, Bahr R, Ekstrand J. Methods for epidemiological study of injuries to professional football players-developing the UEFA model. Br J Sports Med 2005;39:340-6.

25 Olsen OE, Myklebust G, Engebretsen L, Holme I, Bahr R. Exercises to prevent lower limb injuries in youth sports: cluster randomised controlled trial. BMJ 2005;330:449.

26 Lin DY, Wei DJ. The robust inference for the Cox proportional hazards model. J Am Stat Assoc 1989;84:1074-8.

27 Greenland S, Rothman KJ. Introduction to stratified analysis. In: Rothman KJ, Greenland S, Lash TL, eds. Modern epidemiology. Lippincott Williams \& Williams 2008:273-4

28 Altman DG. Confidence intervals for the number needed to treat. BMJ 1998;317:1309-12.

29 Zazulak BT, Hewett TE, Reeves NP, Goldberg B, Cholewicki J. Deficits in neuromuscular control of the trunk predict knee injury risk: a prospective biomechanical-epidemiologic study. Am J Sports Med 2007;35:1123-30.

30 Hewett TE, Myer GD, Ford KR, Heidt RS Jr, Colosimo AJ, McLean SG, et al.

Biomechanical measures of neuromuscular control and valgus loading of the knee predict anterior cruciate ligament injury risk in female athletes: a prospective study. Am J Sports Med 2005;33:492-501.

31 Brophy RH, Wright RW, Matava MJ. Cost analysis of converting from single-bundle to double-bundle anterior cruciate ligament reconstruction. Am J Sports Med 2009;37:683-7.
32 Janssen KW, Orchard JW, Driscoll TR, van Mechelen W. High incidence and costs for anterior cruciate ligament reconstruction performed in Australia from 2003-2004 to 2007-2008: time for an anterior cruciate ligament register by Scandinavian model? Scand J Med Sci Sports 2011; doi: 10.1111/j.1600-0838.2010.01253.x.

33 Pasanen K, Parkkari J, Pasanen M, Hiilloskorpi H, Mäkinen T, Järvinen M, et al. Neuromuscular training and the risk of leg injuries in female floorball players: cluster randomised controlled study. BMJ 2008;337:a295.

\section{Accepted: 23 March 2012}

\section{Cite this as: BMJ 2012;344:e3042}

This is an open-access article distributed under the terms of the Creative Commons Attribution Non-commercial License, which permits use, distribution, and reproduction in any medium, provided the original work is properly cited, the use is non commercial and is otherwise in compliance with the license. See: http://creativecommons.org/licenses/bync/2.0/ and http://creativecommons.org/licenses/by-nc/2.0/legalcode. 


\section{Tables}

\section{Table 1/ Details of neuromuscular warm-up programme used in intervention group}

Exercise Instructions

One legged knee squat: Slow movement with smooth turn, horizontal pelvis and non-supporting foot in front of body with slightly flexed hip and knee

\begin{tabular}{ll} 
Level A & Hands on hips \\
\hline Level B & Hold ball over head with straight arms \\
\hline Level C & Hands on hips; mark with non-supporting foot just above ground at 12-02-04-06 o'clock positions \\
\hline Level D & $\begin{array}{l}\text { Bend down while holding ball and let ball touch ground outside supporting foot; make diagonal movement upwards } \\
\text { and raise ball over head with straight arms on contralateral side }\end{array}$ \\
\hline Pair exercise & $\begin{array}{l}\text { Teammate stands slightly oblique in front of you and ball is pressed between lateral sides of feet of non-supporting } \\
\text { legs }\end{array}$ \\
\hline Pelvic lift: & Supine position; lift pelvis from ground while keeping back straight \\
\hline Level A & Both feet on ground and hands across chest \\
\hline Level B & One foot on ground and contralateral leg flexed in hip and knee $90^{\circ}$ with both hands on knee \\
\hline Level C & One foot on football and contralateral leg flexed in hip and knee $90^{\circ}$ with arms on ground alongside body \\
\hline Level D & $\begin{array}{l}\text { One foot on ground and other in air; keep upper arms on ground with elbows flexed } 90^{\circ} ; \text { push away supporting } \\
\text { foot and land on contralateral foot }\end{array}$ \\
\hline Pair exercise & $\begin{array}{l}\text { Teammate stands with flexed knees and supports heel of one of your feet in her hands; hands across chest and } \\
\text { lift pelvis }\end{array}$ \\
\hline
\end{tabular}

Two legged knee squat: Slow movement with smooth turn, back in straight position and feet shoulder-wide apart with soles in contact with ground

\begin{tabular}{|c|c|c|}
\hline Level A & Hold ball in front of body with straight arms & $3 \times 8-15$ reps \\
\hline Level B & Hands on hips & $3 \times 8-15$ reps \\
\hline Level C & Hold ball over head with straight arms & $3 \times 8-15$ reps \\
\hline Level D & $\begin{array}{l}\text { Same as level } \mathrm{C} \text { but continue movement and rise up on toes after returning to starting position and stay briefly } \\
\text { in that position }\end{array}$ & $3 \times 8-15$ reps \\
\hline Pair exercise & $\begin{array}{l}\text { Teammate stands next to you approximately } 1 \mathrm{~m} \text { away, facing opposite directions; hold ball between you with } \\
\text { one hand and other hand on hip; apply slight pressure on ball while performing knee squat }\end{array}$ & $3 \times 8-15$ reps \\
\hline The bench: & Lift body and keep it in straight line & \\
\hline Level A & Prone position; support on knees and on lower arms with elbows kept under shoulders & $15-30 \mathrm{sec}$ \\
\hline Level B & Same as level A but with support on tip of feet & $15-30 \mathrm{sec}$ \\
\hline Level C & Same as level B, but move foot to side and back to starting position; alternate sides & $15-30 \mathrm{sec}$ \\
\hline Level D & $\begin{array}{l}\text { Lie sideways with support on foot and lower arm with elbow kept under shoulder and other hand on hip; lift hip } \\
\text { off ground and stay briefly in that position with good control before slowly returning to starting position }\end{array}$ & $5-10$ reps \\
\hline Pair exercise & $\begin{array}{l}\text { Teammate stands behind you and holds your feet or lower legs; lift the body and walk forward by using hands on } \\
\text { ground }\end{array}$ & $15-30 \mathrm{sec}$ \\
\hline The lunge: & Take deep step with marked knee lift and soft landing; rear knee should not touch ground & \\
\hline Level A & Hands on hips; move forward with each step & $3 \times 8-15$ reps \\
\hline Level B & $\begin{array}{l}\text { Hold ball in front of body with straight arms; rotate upper body while stepping forward and position ball laterally } \\
\text { of front leg; move forward with each step and alternate sides }\end{array}$ & $3 \times 8-15$ reps \\
\hline Level C & $\begin{array}{l}\text { Hold ball over head with straight arms; perform forward lunge and push back with front leg and return to starting } \\
\text { position }\end{array}$ & $3 \times 8-15$ reps \\
\hline Level D & Hold ball in front of body with straight arms; perform sideways lunge and return to starting position & $3 \times 8-15$ reps \\
\hline Pair-exercise & Teammate stands in front of you 5-10 m away; perform forward lunge while making throw-in with ball & $3 \times 8-15$ reps \\
\hline Jump/landing: & Make jump with soft landing; stay briefly in landing position & \\
\hline Level A & $\begin{array}{l}\text { Stand on one leg with knee slightly bent and hands on hips; make short forward jump and land on same foot; } \\
\text { jump backwards to starting position }\end{array}$ & $3 \times 8-15$ reps \\
\hline Level B & $\begin{array}{l}\text { Stand on two legs shoulder-wide apart with hands on back; make sideways jump and land on one foot; alternate } \\
\text { sides }\end{array}$ & $3 \times 8-15$ reps \\
\hline Level C & Take a few quick steps on same spot and make short jump straight forward landing on one foot & $3 \times 5$ reps \\
\hline Level D & Same as level C, but change direction and jump to one side ( $90^{\circ}$ turn); alternate sides & $3 \times 5$ reps \\
\hline Pair exercise & $\begin{array}{l}\text { Teammate stands in front of you approximately } 5 \mathrm{~m} \text { away; make two legged jump while heading football and land } \\
\text { on two legs }\end{array}$ & $3 \times 8-15$ reps \\
\hline
\end{tabular}


Table 2| Baseline characteristics and exposure data. Values are numbers (percentages) unless stated otherwise

\begin{tabular}{|c|c|c|}
\hline Variable & Intervention group ( $n=2479$ players) & Control group ( $n=2085$ players) \\
\hline \multicolumn{3}{|l|}{ Characteristics } \\
\hline No of clubs & 121 & 109 \\
\hline No of teams & 184 & 157 \\
\hline Mean (SD) age (years) & $14.0(1.2)$ & $14.1(1.2)$ \\
\hline \multicolumn{3}{|l|}{ Age (years): } \\
\hline 12 & $159(6)$ & $116(6)$ \\
\hline 13 & $783(32)$ & $650(31)$ \\
\hline 14 & $741(30)$ & $594(28)$ \\
\hline 15 & $471(19)$ & $424(20)$ \\
\hline 16 & $227(9)$ & $208(10)$ \\
\hline 17 & $98(4)$ & $93(4)$ \\
\hline Mean (SD) height $(\mathrm{cm})$ & $163.5(6.8)$ & $163.8(6.6)$ \\
\hline Mean (SD) weight $(\mathrm{kg})$ & $53.3(8.6)$ & $53.3(8.4)$ \\
\hline Menarche & $1726 / 2321(74)$ & $1474 / 1967(75)$ \\
\hline Previous acute knee injury & $215 / 2396(9)$ & $161 / 2011(8)$ \\
\hline Previous ACL injury & $23 / 2396(0.96)$ & $16 / 2011(0.8)$ \\
\hline Current knee complaints & $583 / 2396(24)$ & $504 / 2011(25)$ \\
\hline Familiar disposition of ACL injury & $361 / 2325(16)$ & 295/1976 (15) \\
\hline \multicolumn{3}{|l|}{ Clubs' exposure } \\
\hline Mean (SD) training sessions per season & $39.8(12.1)$ & $41.6(11.3)$ \\
\hline Mean (SD) matches per season & $20.0(8.0)$ & $20.1(7.2)$ \\
\hline Mean (SD) training sessions per week & $1.8(0.3)$ & $1.8(0.3)$ \\
\hline Mean (SD) matches per week & $0.9(0.3)$ & $0.9(0.3)$ \\
\hline \multicolumn{3}{|l|}{ Players' exposure } \\
\hline Mean (SD) training sessions per season & $28.8(13.1)$ & $30.2(12.3)$ \\
\hline Mean (SD) matches per season & $16.5(8.5)$ & $16.4(7.6)$ \\
\hline Mean (SD) training sessions per week & $1.3(0.5)$ & $1.3(0.5)$ \\
\hline Mean (SD) matches per week & $0.7(0.3)$ & $0.7(0.3)$ \\
\hline Mean (SD) training hours per season & $44.0(20.9)$ & $45.4(18.8)$ \\
\hline Mean (SD) match hours per season & $16.2(9.6)$ & $16.5(9.2)$ \\
\hline Mean (SD) training attendance per season* & $69.0(21.7)$ & $68.7(21.0)$ \\
\hline Players with match play with other teams $\dagger$ & $706(28)$ & $488(23)$ \\
\hline
\end{tabular}

$\mathrm{ACL}=$ anterior cruciate ligament.

${ }^{*}$ Calculated as percentage of eligible team training sessions player participated in during season.

†Players who played matches with district or national team or another team within club during study inclusion. 


\begin{tabular}{|c|c|c|c|c|c|c|c|c|c|}
\hline Injury date & Group & Age & Activity & Limb & Contact & MRI & Type of tear & $\begin{array}{l}\text { Associated } \\
\text { lesions }\end{array}$ & $\begin{array}{c}\mathrm{ACL} \\
\text { reconstruction }\end{array}$ \\
\hline 13 April & Control & 14 & Match & Left & Yes & Yes & Total & $\mathrm{MCL}$ & No \\
\hline 18 April & Control & 14 & Match & Left & Yes & Yes & Total & MCL and LM & No \\
\hline 18 April & Control & 16 & Training & Left & No & Yes & Total & No & Yes \\
\hline 22 April & Control & 16 & Training & Left & No & $\mathrm{No}^{*}$ & Partial† & $\mathrm{MCL}$ & No \\
\hline 10 May & Intervention & 14 & Match & Left & No & Yes & Total & No & Yes \\
\hline 11 May & Control & 15 & Training & Left & No & $\mathrm{No}^{*}$ & Partial¥ & $\mathrm{MM}$ & No \\
\hline 17 May & Control & 14 & Match & Left & Yes & Yes & Total & LM & No \\
\hline 25 May & Control & 15 & Match & Right & No & Yes & Total & LCL & Yes \\
\hline 9 June & Control & 14 & Match & Left & Yes & Noß & Partialף & No & No \\
\hline 17 June & Intervention & 15 & Match & Left & No & Yes & Total & No & Yes \\
\hline $7 \mathrm{Jul}$ & Intervention & 15 & Match & Left & No & Yes & Total & No & Yes \\
\hline 25 July & Intervention & 14 & Match & Right & Yes & Yes & Total & No & Yes \\
\hline 31 July & Control & 14 & Match & Right & Yes & Yes & Total & No & No \\
\hline 6 August & Control & 16 & Training & Left & No & Yes & Total & No & Yes \\
\hline 8 August & Control & 15 & Match & Right & No & Yes & Total & $\mathrm{MCL}$ & No \\
\hline 9 August & Intervention & 17 & Match & Left & Yes & Yes & Total & No & Yes \\
\hline 10 August & Control & 14 & Training & Right & No & Yes & Total & MM & Yes \\
\hline 29 August & Control & 13 & Match & Right & No & Yes & Total & MM & Yes \\
\hline 11 September & Intervention & 16 & Match & Right & No & $\mathrm{No}^{* *}$ & Total & No & Yes \\
\hline 20 September & Control & 16 & Match & Right & Yes & Yes & Total & MCL and LM & Yes \\
\hline 4 October & Intervention & 15 & Match & Left & No & Yes & Partialt† & No & No \\
\hline
\end{tabular}

$\mathrm{LCL=lateral} \mathrm{collateral} \mathrm{ligament;} \mathrm{LM}=$ lateral meniscus; $M C L=$ medial collateral ligament; $M M=$ =medial meniscus; $M R I=$ magnetic resonance imaging.

*Subacute arthroscopy instead of MRI.

†Tear of anteromedial bundle with increased anterioposterior translation and negative pivot shift diagnosed during clinical examination under anaesthesia and arthroscopy.

‡Partial ACL tear with increased anterioposterior translation and negative pivot shift diagnosed during arthroscopy for locked knee due to bucket handle tear of MM.

§Injury not treated by medical support of study.

IPartial ACL tear with increased anterioposterior translation and negative pivot shift diagnosed at repeated clinical examination in subacute phase.

${ }^{* *}$ Player declined initial MRI, and diagnosis was confirmed later during ACL reconstruction.

††Partial ACL tear with increased anterioposterior translation and tendency to positive pivot shift diagnosed at repeated clinical examination in subacute phase. 
Table 4| Effectiveness of neuromuscular warm-up programme in adolescent female football players according to intention to treat. Values are numbers (percentages) of injured players unless stated otherwise

\begin{tabular}{|c|c|c|c|c|}
\hline Injuries & $\begin{array}{c}\text { Intervention group ( } \mathrm{n}=\mathbf{2 4 7 9} \\
\text { players) }\end{array}$ & Control group ( $\mathrm{n}=2085$ players) & Rate ratio $(95 \% \mathrm{Cl})^{*}$ & $P$ value \\
\hline Anterior cruciate ligament injury & $7(0.28)$ & $14(0.67)$ & 0.36 (0.15 to 0.85$)$ & 0.02 \\
\hline Severe knee injury & $26(1.05)$ & $31(1.49)$ & 0.70 (0.42 to 1.18$)$ & 0.18 \\
\hline Any acute knee injury & $48(1.94)$ & $44(2.11)$ & $0.92(0.61$ to 1.40$)$ & 0.71 \\
\hline
\end{tabular}

${ }^{*}$ Rate ratios from unadjusted analyses, stratified by district, using Cox regression with robust variance estimation to account for correlation of outcomes within each club. ${ }^{26}$ 


\section{Figure}

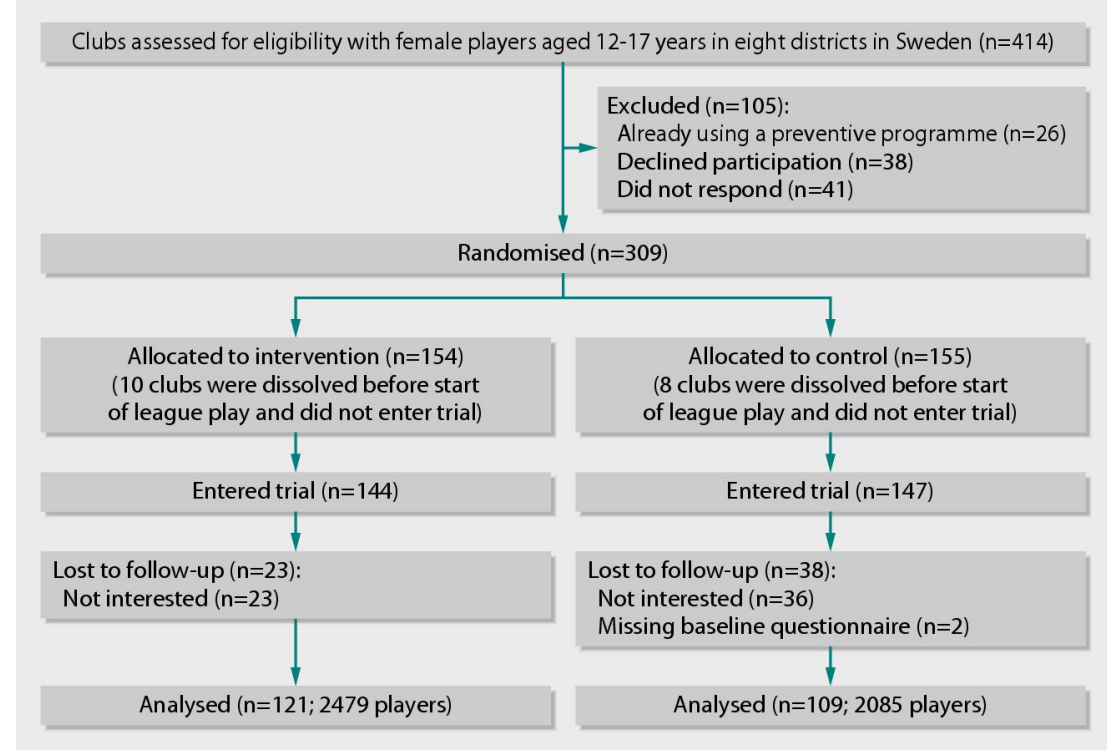

Flow of clubs through trial 